\title{
A Brief Review of Clinical Features of Coronavirus Disease 2019 (COVID-19) in Algeria
}

\author{
Mohamed Lounis ${ }^{1 *}$ \\ ${ }^{1}$ Department of Agro-veterinary Science, Faculty of Natural and Life Sciences, University of Ziane Achour, Djelfa, ALGERIA \\ *Corresponding Author: lounisvet@gmail.com
}

Citation: Lounis, M. (2021). A Brief Review of Clinical Features of Coronavirus Disease 2019 (COVID-19) in Algeria. European Journal of Environment and Public Health, 5(2), em0078. https://doi.org/10.21601/ejeph/10955

ARTICLE INFO

Received: 2 Dec. 2020

Accepted: 6 Feb. 2021

\begin{abstract}
Purposes: The objective of the current work is to highlight the most common clinical and biological characteristics and potential risk factors of COVID-19 in Algeria.

Methods: This study was conducted using data of four published studies about clinical, biological characteristics and risk factors for severity and mortality of COVID-19 realized in three hospitals (Beni Messous, Bologhine and Rouiba) in the department of Algiers (Algeria).

Results: Results showed that cough, fever and asthenia were the most common clinical signs in COVID-19 positive patients. The median age of the presented cases was 54.4 years and $61 \%$ of them were older than 50 years. Also, $68 \%$ of them have at least one related comorbidity where diabetes and hypertension were the most common. Elevated sedimentation rate, elevated LDH, elevated CRP, elevated ALT/AST and lymphopenia were the most common biological abnormalities observed.
\end{abstract}

Conclusion: This work despite some limitations could contribute to the clinical characterization of COVID-19 in Algeria.

Keywords: COVID-19, Coronavirus, clinical features, risk factors, Algeria

\section{INTRODUCTION}

The novel Coronavirus respiratory disease 2019 (COVID19) has not stopped expanding and impressing the world since it started in Wuhan (China) on December 2019 (Palacio Cruz et al., 2020). With more than 11.8 millions positive cases in more than 213 countries and regions and more than 543,000 deaths, the disease has exceeded all expectations (World meter, 2020).

From the first COVID-19 positive cases reported on February 25, Algeria accounts currently 16879 cases (July 7). This number puts it as the fifth most affected country in Africa after South Africa, Egypt, Nigeria and Ghana. However it is listed in the third range by the number of deaths with 968 cases translating a fatality rate of 5.7\% (World meter, 2020).

The clinical and biological characteristics and potential risk factors of COVID-19 still be under study and multiple researches are ongoing to fully understand this chapter. Reported results showed that this disease is widely dominated by respiratory symptoms (Perisetti et al., 2020). Pneumonia, cough and fever are the most common and are responsible for most of the morbidity and mortality (Cao et al., 2020; Marei et al, 2020; Yasuhara et al., 2020). However, extra-pulmonary manifestations such as nausea, vomiting, anorexia, diarrhea, and abdominal pain are also increasingly recognized as important symptoms (Perisetti et al., 2020).

On the other hand, it has been shown that certain comorbidities like diabetes, chronic obstructive pulmonary disease, cardiovascular diseases, hypertension, and other disease could contribute to the severity of the COVID-19 disease and death (Ejaz et al., 2020; Marei et al., 2020; Yan et al., 2020)

Despite the huge data in relation with this field in the world, little is known in Algeria. The existing data consists on some published studies with low numbers of patients in some hospitals in Algiers, the capital of Algeria.

In this way, the present work was conducted to review and to highlight the common clinical signs and potential risk factors of COVID-19 in Algeria from the available data.

\section{METHODS}

This study was realized using data of four published studies about clinical, biological characteristics and risk factors for severity and mortality of COVID-19 in Algeria. These studies were conducted in three hospitals (Beni Messous, Bologhine and Rouiba) in the department of Algiers (Algeria). They 
Table 1. Characteristic of the different studies

\begin{tabular}{|c|c|c|c|c|c|c|c|c|c|}
\hline Reference & Type & Period & $\begin{array}{c}\text { Total } \\
\text { number }\end{array}$ & $\begin{array}{c}\text { Confirmed } \\
\text { cases }\end{array}$ & $\begin{array}{c}\text { Median } \\
\text { age }\end{array}$ & $\begin{array}{c}\text { Sexe } \\
(\text { Men \%) }\end{array}$ & Deaths & $\begin{array}{c}\text { Duration of } \\
\text { treatment (day) }\end{array}$ & Comorbidity \\
\hline $\begin{array}{l}\text { Kadi et al. } \\
(2020)\end{array}$ & Retrospective & Mar-May & 65 & 65 & 54 & 58.5 & 1 & 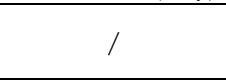 & $80 \%$ \\
\hline $\begin{array}{c}\text { Brahimi et al. } \\
(2020)\end{array}$ & Prospective & Mar11- April 30 & 3324 & 434 & 56.1 & 55.5 & 63 & 9.55 & $56.7 \%$ \\
\hline $\begin{array}{c}\text { Kefti et al. } \\
(2020)\end{array}$ & Prospective & Mar 19- April30 & 139 & 86 & 53 & 60.5 & 1 & 7 & 70 \\
\hline $\begin{array}{l}\text { Aouameur et } \\
\text { al. }(2020)\end{array}$ & Prospective & Mar 31- May 13 & 30 & 30 & 65.7 & 73.3 & 13 & 10.5 & / \\
\hline
\end{tabular}

consisted of a retrospective study in the pneumology service of the hospital of Beni Messous (Kadi et al., 2020) and three prospective studies: one study in the hospital of Beni Messous (Brahimi et al., 2020), another in the hospital of Rouiba (Kefti et al., 2020) and the last one concerns the severe cases reported in the hospital of Bologhine (Aouameur et al., 2020).

All these studies were conducted between March and May, 2020, the period which characterizes the emergence and the spreading of the pandemic in Algeria (Table 1).

Data were collected and statistically treated using Excel software.

\section{RESULTS AND DISCUSSION}

\section{Demographic Characteristics}

In these studies a total of 615 COVID-19 positive patients were followed up including 75 severe cases presented in the three hospitals in the department of Algiers (Beni Messous, Bologhine and Rouiba).

The median age of the presented cases was 54.4 years. Furthermore, more than $61 \%$ were more than 50 years old. The national reports in the same period indicated that $56.6 \%$ of patients were more than 50 years old (Lounis, 2020). Of notes, the median age reported in these studies is included in the intervals of ages reported in different countries varying from 44 to 67.5 (Aggarwal et al., 2020; Chen et al., 2020; Colaneri et al., 2020; Louhaichi et al., 2020; Wu et al., 2020; Yan et al., 2020; Zhang et al., 2020a).

Results showed also that, $58.2 \%$ of the total cases were men, which are near the national median reported in this period of $56.5 \%$ (Lounis, 2020). This rate seems to be higher than the available data from the neighboring country of Tunisia (Louhaichi et al., 2020) but included in the different reported rates from different countries (Aggarwal et al., 2020; Cao et al., 2020; Chen et al., 2020; Huang et al., 2020a; Yu et al., 2020).

Regarding severe cases and deaths, results showed that the median age of patient was estimated at 65.7 years. Also, $70 \%$ were more than 57 years old (Aouameur et al., 2020) and $62.2 \%$ were more than 65 years (Kefti et al., 2020).

The median age of mortality is estimated at 73.5 years old (Aouameur et al., 2020). This is higher than the median age reported by Xie et al. (2020) (70 years), and Cao et al. (2020) (71 years) but lower than those reported by Chen et al. (2020) (77 years), and Palmieri et al. (2020) (78.5 years).
In this way, it is well established that patients over 60 years showed heavier clinical manifestations, greater severity and longer disease courses and mortality compared with those less than 60 years (Liu et al., 2020). In fact, several reports revealed that most of deaths are associated with elder patients. These studies reported that $95.4 \%$ of total dead persons were more than 45 year and $73.3 \%$ were more than 65 years old (NYVH, 2020 ). On the other hand, the case fatality rate in the age group until the end of the forties was not more than $0.2 \%-0.4 \%$ while it increases to $14.8 \%$ in the age group older than 80 years (NYCH, 2020). Chen et al. (2020) reported that the mortality rate was $34.5 \%$ in patients of more than 65 years while it was estimated at $4.7 \%$ for those of less than 65 years old.

In Algeria, even not precisely established, available data reported that $75 \%$ of the total died persons in the country were older than 60 years (Algerian health ministry, 2020). This risk posed by old age to COVID-19 mortality could be explained by their weak immune systems but also by the risk related of this age to comorbidities magnifying the risk of dying from COVID19 (Medina, 2020).

The case fatality rate is estimated at $12.7 \%$ (Aouameur et al., 2020; Kefti et al., 2020) and 56\% among the severe cases studied by Aouameur et al. (2020) died.

Results showed also that men seemed to be more affected with severe cases than women in the department of Algiers (73.3\%). This result is in accordance with the national rate (Lounis, 2020) and some international published rate (Xie et al., 2020).

Even not well elucidated, this higher incidence in male patients could possibly be explained by more exposure by the male counterparts of the family for foray outside homes and partly by the higher concentration of Angiotensin-converting enzyme-2 (ACE-2) in men than in women (Aggarawal et al., 2020).

\section{Clinical Signs}

From the cases studied, multiple clinical manifestations were observed. Cough (66\%), fever (64.6\%) and asthenia (53.3\%) were the most frequent. These symptoms, in association with dyspnea were the most reported in the severe cases (Table 2).

It is well established that cough, fever, asthenia and dyspnea are the most common symptoms observed in COVID19 patients since the first reports from China (Cao et al., 2020; Chen et al., 2020, Yan et al., 2020). This was confirmed by Fu et al., (2020), in a meta-analysis including several studies who reported that fever (83.3\%), cough (60.3\%) and fatigue (38.0\%) were the most common. 
Table 2. Clinical features of COVID-19 patients in Algeria

\begin{tabular}{ccc}
\hline Clinical signs & Total cases (\%) & Severe cases (\%) \\
\hline Fever & 64.6 & 52.8 \\
\hline Cough (dry) & 66 & 57.5 \\
\hline Diarrhoea & 32.3 & 10 \\
\hline Asthenia & 53.3 & 58.8 \\
\hline Anosmia/agueusia & $/$ & 10.2 \\
\hline Myalgia/soreness & 30.8 & 10 \\
\hline Nausea/vomiting & 26.7 & $/$ \\
\hline Abdominal pain & 9.2 & 8.7 \\
\hline Headache & 6.5 & 56 \\
\hline Hemoptysis & 25.5 & 23 \\
\hline Dyspnea & 1.9 & 16 \\
\hline Respiratory distress & 27.5 & $/$ \\
\hline pharyngal Irritation/ Odynophagie & $/$ & $/$ \\
\hline Anorexia & 10.9 & $/$ \\
\hline Chest pain & 50 & $/$ \\
\hline Ocular burninig & 5.8 & $/$ \\
\hline Rhinorhea & 1.1 & $/$ \\
\hline Vertigo & 1.1 & \\
\hline
\end{tabular}

Table 3. COVID-19 and associated comorbidities in Algeria

\begin{tabular}{|c|c|c|}
\hline Comorbidity & Total cases (\%) & Severe cases (\%) \\
\hline Hypertention & 35.6 & 39.5 \\
\hline Diabetes & 24.9 & 36.2 \\
\hline Cardiovascular diseases & 8 & 13.4 \\
\hline Renal diseases & 3.2 & $4.4 \%$ \\
\hline Respiratory diseases & 9.2 & $25.6 \%$ \\
\hline Neurological signs & 2.4 & - \\
\hline Tabagism & 12.8 & $2.2 \%$ \\
\hline Obesity & 1.4 & - \\
\hline Immunodepression & 1.5 & $4.4 \%$ \\
\hline Hyperthyroïdia & 13.3 & - \\
\hline Others & 13.2 & 37.3 \\
\hline
\end{tabular}

Like the reported clinical signs by Zhang et al. (2020b), moderate degree of gastrointestinal symptoms was also reported with different rates such as anorexia $(50 \%)$ and diarrhea 32.3\% (Table 2). If Piresseti et al. (2020) stated that gastrointestinal manifestations are increasingly recognized as important symptoms, Huang et al. (2020a), however, reported that COVID-19 patients rarely developed intestinal signs. The same authors reported that upper respiratory tract symptoms (rhinorrhoea, sneezing, or sore throat) were rarely observed suggesting that the target cells might be located in the lower airway.

At last, it is well known that time from onset of symptoms to first hospital admission is important in the evolution of the disease. In the studied works, the median time was estimated at 8.1 days. This time is higher than those reported in China varying from 3.5 to 7 days (Cao et al., 2020; Huang et al., 2020a; Zhang et al., 2020b).

\section{Underlying Conditions}

In the cited studies, $68.9 \%$ of the total admitted patients have at least one related comorbidity. This result is in accordance with the published reports in different countries. If Guan et al. (2020a) and Zhao et al. (2020) reported a relatively low rates of patients with comorbidities of about $23 \%$, other studies reported a rate of $63.7 \%$ (Colaneri et al., 2020). Also, 76.5 and $74.4 \%$ of patients with severe cases and mortality respectively have at least one related comorbidity (Xie et al., 2020).

Results showed also that hypertension (35.6\%) and diabetes $(24.9 \%)$ were the most common co-existing illness and the most underlying condition associated with the risk of severity and mortality were hypertension (39.5\%), diabetes (35.2\%), respiratory diseases $(25,6 \%)$ and cardiovascular diseases (13.4\%) (Table 3).

In this way, patients with concomitant diseases are significantly more likely to develop severe COVID-19 disease (Ejaz et al., 2020; Guan et al., 2020b; Huang et al., 2020b, Zhu et al., 2020) and different studies have reported the possible relation between comorbidities and COVID-19 mortality. Xie et al. (2020) reported that hypertension (50.0\%), followed by diabetes $(25.0 \%)$ and ischemic heart disease (18.5\%) were the most common comorbidities associated with mortality.

On the other hand, while the fatality rate was estimated at $0.9 \%$ in patients without co-morbidities, it was estimated at $13.2 \%, 9.2 \%, 8.4 \%, 8 \%$ and $7.6 \%$ for those with cardio-vascular disease, diabetes, hypertension, chronic respiratory disease and Cancer respectively (Zhang et al., 2020c).

In Algeria, $12.8 \%$ of the positive patients were smokers. This is in accordance with the available data in the world. However, the potential relation of tabagism and COVID-19 still be controversial. If certain authors state that smoking is 
Table 4. Biological abnormalities associated With COVID-19

\begin{tabular}{cc}
\hline Biological parameters & Rate (\%) \\
\hline ElevatedLactate dehydrogenase (LDH) & $63.8^{\mu}$ \\
\hline Elevated CRP C-reactive protein & $59.9^{\mu}$ \\
\hline Elevated AST/ALT & $50.8^{*}$ \\
\hline Anemia & $37.1^{*}$ \\
\hline Leucopenia & 10.7 \\
\hline Lymphopenia & $42.1^{*}$ \\
\hline Neutropenia & $3.1^{\mu}$ \\
\hline Elevated D-Dimeres & $27.7^{\mu}$ \\
\hline Elevated CPK & $28.8^{\times}$ \\
\hline Hepatical cytolysis & $27.6^{\times}$ \\
\hline Hyponatremia & $20.3^{\times}$ \\
\hline Hyper-uremia & $20^{\times}$ \\
\hline Elevated prothrombine & $19.4^{\times}$ \\
\hline Hypercreatinine & $10.7^{\times}$ \\
\hline Hypokalemia & $5.1^{\times}$ \\
\hline Hypernatremia & $5.1^{\times}$ \\
\hline Hyperkalemia & $3.4^{\times}$ \\
\hline Elevated sedimentation rate & $84.4^{\times}$ \\
\hline Hyperleucocytosis & $12^{\times}$ \\
\hline Thrombopenia & $6.8^{\times}$ \\
\hline Thrombocytosis & $6.8^{\times}$ \\
\hline Polycethemia & $2.7^{\times}$ \\
\hline ALT & \\
\hline Alaspartate aning
\end{tabular}

ALT : Alanine aminotransferase, AST : Aspartate aminotransferase

${ }^{\mu}$ Reference (Kadi et al., 2020 and Kefti et al., 2020)

* Reference (Kadi et al., 2020).

${ }^{\times}$Reference (Kefti et al., 2020)

an important risk factor associated with progression of the disease (Jordan et al., 2020; Patanavanich et al., 2020; Rahman et al., 2020), a recent study from 38 European countries has found that there is no association between smoking and COVID-19 (Tsigaris and Teixeira da Silva, 2020). Also in our reviewed studies, only 2 (2.2\%) out of 45 patients with severe cases were smokers (Aouameur et al., 2020). The weak association between smoking and the severity of the disease may be due to the lower levels of ACE2 in smokers (Yu et al., 2020).

\section{Biological Characteristics}

Multiple biological modifications were associated with COVID-19 infection. The laboratory parameters of COVID-19 patients in Algeria are shown in Table 4. Elevation of sedimentation rate was the most common abnormality observed in $94.4 \%$ of patients. Secondarily, elevated LDH levels (63.8\%), elevated C-reactive protein (CRP) (59.9\%), elevated ALT/AST (50.8\%) and lymphopenia (42.1\%) were the most common in the monitored patients. Also, lymphopenia was one of the most observed abnormalities associated with severe cases (66\%). Of notes, the low level of lymphocyte counts has been linked to prognosis of COVID-19 and was considered as a reference index in its diagnosis (Aggarwal et al., 2020).

Theses results are in accordance with the results of the meta-analysis review of Fu et al. (2020) who reported that, CRP (68.6\%), lymphopenia (57.4\%) and raised LDH (51.6\%) were the most common in different studies. In fact, elevated LDH has been related to hematological malignancy and acute lung injury and might reflect tissue necrosis related to poor clinical outcome and may be a useful to test parameter to identify patients at risk for severe respiratory failure (Aggarwal et al., 2020).

For CRP and even it was not fully related to viral infections, an increasing was reported in influenza acute respiratory infection suggesting that its elevation may be due to the tissue destruction (Aggarwal et al., 2020).

Our results showed that in addition to lymphopenia, elevated D-dimere (74\%), elevated procalcitonin (46\%) and hyperleucocytosis were associated with severe cases (Aouameur et al., 2020). Past reports suggested that elevated creatinine and elevated procalcitonin levels were predominantly associated with severe cases and death (Chen et al., 2020; Zhao et al., 2020).

\section{Study Limitations}

The current study has presented some limitations which are essentially related to the small number of published studies in Algeria and consequently the number of monitored COVID-19 patients. Also, some differences in the methodology were observed knowing that theses studies have been conducted for a short duration and in different period. Also, the clinical, biological and epidemiological criteria included were not standardized in all these studies.

\section{CONCLUSIONS AND RECOMMENDATIONS}

This review despite some limitations highlights the common clinical, biological and potential risk factors of COVID-19 in Algeria. The most common clinical signs reported in COVID-19 positive patients were cough, fever and asthenia. The most biological abnormalities were elevated sedimentation rate, elevated $\mathrm{LDH}$, elevated CRP, elevated 
ALT/AST and lymphopenia. Also, most of cases (60\%) are elder patients of more than 50 years and men are more affected than women. At last, the study revealed that $68 \%$ of the COVID-19 patients had at least, one related comorbidity and diabetes and hypertension were the most common and were more often associated with severe cases.

As a recommendation, extending such studies for other available data in different department could be of great importance in order to better understand and characterize clinical, biological and epidemiological characteristics of COVID-19 in Algeria.

Funding: No external funding is received for this article.

Declaration of interest: The author declares having no conflict of interest related to this work.

Ethics approval and consent to participate: Not applicable.

Availability of data and materials: All data generated or analyzed during this study are available for sharing when appropriate request is directed to corresponding author.

\section{REFERENCES}

Aggarwal, A., Shrivastava, A., Kumar, A. and Ali, A. (2020). Clinical and Epidemiological Features of SARS-CoV-2 Patients in SARI Ward of a Tertiary Care Centre in New Delhi. Journal of the Association of Physicians of India, 68, 19-26.

Algerian Health Ministry. (2020). Carte épidémiologique. Available at: https://www.covid19.gov.dz/carte/ (Accessed: July 7, 2020).

Aouameur, A., Ait Amir, A., Amroun, L., Anik, K., et al. (2020). Facteurs de risque de gravité et de mortalité chez les patients adultes COVID-19. Revue Algérienne d'allergologie, 5(1), 121-127.

Brahimi, G., Larinoun, A., Ait Seddik, S., Cheboub, N., et al. (2020). Étude épidémiologique des patients atteints de Covid-19 reçus au CHU Béni-Messous du 11 Mars-30 Avril 2020: Résultats préliminaires. Revue Algérienne d'allergologie, 5(1), 100-106.

Cao, Z., Li, T., Liang, L., Wang, H., et al. (2020). Clinical characteristics of Coronavirus Disease 2019 patients in Beijing, China. PLoS One, 15(6), e0234764. https://doi.org/10.1371/journal.pone.0234764

Chen, T. L., Dai, Z., Mo, P., Li, X., et al. (2020). Clinical Characteristics and Outcomes of Older Patients with Coronavirus Disease 2019 (COVID-19) in Wuhan, China: A Single-Centered, Retrospective Study. The Journals of Gerontology: Series A, 75(9), 1788-1795. https://doi.org/10.1093/gerona/glaa089

Colaneri, M., Sacchi, P., Zuccaro, V., Biscarini, S., et al. (2020). Clinical characteristics of coronavirus disease (COVID-19) early findings from a teaching hospital in Pavia, North Italy, 21 to 28 February 2020. Eurosurveillance, 25(16), pii $=2000460$.

https://doi.org/10.2807/15607917.ES.2020.25.16.2000460
Ejaza, H., Alsrhani, A., Zafar, A., Javed, H., et al. (2020). COVID-19 and comorbidities: Deleterious impact on infected patients. Journal of Infection and Public Health, 13(12), 1833-1839. https://doi.org/10.1016/j.jiph.2020.07. 014

Fu, L., Wang, B., Yuan, T., Chen, X., et al. (2020). Clinical characteristics of coronavirus disease 2019 (COVID-19) in China: A systematic review and meta-analysis. Journal of Infection, 80, 656-665. https://doi.org/10.1016/j.jinf.2020. 03.041

Guan, W., Liang, W., Zhao, Y., et al. (2020b). Comorbidity and its impact on 1590 patientswith COVID-19 in China: a nationwide analysis. European Respiratory Journal, 55, 2000547. https://doi.org/10.1183/13993003.00547-2020

Guan, W., Ni, Z., Hu, Y., Liang, W., et al. (2020a). Clinical characteristics of 2019 novel coronavirus infection in China. The New England Journal of Medicine, 382, 17081720. https://doi.org/10.1056/NEJMoa2002032

Huang, C., Wang, Y., Li, X., Ren, L., et al. (2020a). Clinical features of patients infected with 2019 novel coronavirus in Wuhan, China. Lancet, 395, 497-506. https://doi.org/10.1016/S0140-6736(20)30183-5

Huang, R., Zhu, L., Xue, L., Liu, L., et al. (2020b). Clinical findings of patients with coronavirus disease 2019 in Jiangsu province, China: A retrospective, multi-center study. PLoS Neglected Tropical Diseases, 14(5), e0008280. https://doi.org/10.1371/journal.pntd.0008280

Jordan, R. E., Adab, P. and Cheng, K. K. (2020). COVID-19: risk factors for severe disease and death. BMJ, 368, m1198. https://doi.org/10.1136/bmj.m1198

Kadi, A., Kheliouen, A., Hadadou, L., Alihalassa, S., et al. (2020). Les caractéristiques des patients pris en charge pour une infection COVID-19 dans un service de pneumologie. Revue Algérienne d'allergologie, 05(01), 113120.

Ketfi, A., Chabati, O., Chemali, S., Mahjoub, M., et al. (2020). Profil clinique, biologique et radiologique des patients Algériens hospitalisés pour Covid-19: données préliminaires. Pan African Medical Journal, 35(2), 77.

Liu, Y., Mao, B., Liang, S., Lu, H.-W., et al. (2020). Association Between Ages and Clinical Characteristics and Outcomes of Coronavirus Disease 2019. European Respiratory Journal, 55, 2001112. https://doi.org/10.1183/13993003.011122020

Louhaichi, S., Allouche, A., Baili, H., Jrad, S., et al. (2020). Features of patients with 2019 novel coronavirus admitted in a pneumology department: The first retrospective Tunisian case series. La Tunisie Medicale, 98(4), 261-265.

Lounis, M. (2020). A Descriptive Study of the Current Situation of COVID-19 in Algeria. Electronic Journal of General Medicine, 17(6), em253. https://doi.org/10.29333/ejgm/ 8287

Marei, R. M., Emara, M. M., Elsaied, O. M., Nasrallah, G. K., et al. (2020). Demographic and Clinical Characteristics of Early Travel-Associated COVID-19 Cases. Frontiers in Public Health, 8, 573925. https://doi.org/10.3389/fpubh. 2020.573925 
Medina, M. A. P. (2020). Age as a Risk Factor of COVID-19 Mortality in the Philippines. https://doi.org/10.2139/ ssrn.3579145

New York City Health. (2020). Coronavirus disease 2019 (COVID-19), Daily Data Summary. April 16 ${ }^{\text {th }}, 2020$.

Palacio Cruz, M., Santos, E., Velázquez Cervantes, M.A., León Juárez, M (2020). COVID-19, a world public health emergency. Revista Clínica Española, 221(1), 55-61. https://doi.org/10.1016/j.rce.2020.03.001

Palmieri, L., Andrianou, X., et al. (2020). Characteristics of COVID-19 patients dying in Italy Report based on available data on March 20th, 2020.

Patanavanich, R. and Glantz, S. A. (2020). Smoking is associated with COVID-19 progression: a meta-analysis. Nicotine Tobacco Research, 22(9), 1653-1656. https://doi.org/10.1093/ntr/ntaa082

Perisetti, A., Gajendran, M., Mann, R., Elhanafid, S. and Goyal H. (2020). COVID-19 extrapulmonary illness-special gastrointestinal and hepatic considerations. Disease- $a-$ Month, 66, 101064. https://doi.org/10.1016/j.disamonth. 2020.101064

Rahman, A. and Sathi, N. J. (2020). Risk factors of the severity of COVID-19: A meta-analysis. The International Journal of Clinical Practice, e13916. https://doi.org/10.1101/2020.04. 30.20086744

Tsigaris, P. and Teixeira da Silva, J. A. (2020). Smoking prevalence and COVID-19 in Europe. Nicotine \& Tobacco Research, 22(9), 1646-1649. https://doi.org/10.1093/ntr/ ntaa121

Worldmer (2020). COVID-19 coronavirus pandemic Uptade. Available at: https://www.worldometers.info/coronavirus/ (Accessed: 7 July 2020).

Wu, J., Wu, X., Zeng, W., Guo, D., et al. (2020). Chest CT findings in patients with Coronavirus disease 2019 and its relationship with clinical features. Investigative Radiology, 55(5), 257-261. https://doi.org/10.1097/RLI.00000000000 00670
Xie, J., Tong, Z., Guan, X., Du, B. and Qiu, H. (2020). Clinical characteristics of patients who died of Coronavirus disease 2019 in China. JAMA Network Open, 3(4), e205619. https://doi.org/10.1001/jamanetworkopen.2020.5619

Yan, Y., Yang, Y., Wang, F., Ren, H., et al. (2020). Clinical characteristics and outcomes of patients with severe COVID-19 with diabetes. BMJ Open Diabetes Research \& Care, 8, e001343. https://doi.org/10.1136/bmjdrc-2020001343

Yasuhara, J., Kuno, T., Takagi, H. and Sumitomo, N. (2020). Clinical characteristics of COVID-19 in children: A systematic review. Pediatric Pulmonology, 55(10), 25652575. https://doi.org/10.1002/ppul.24991

Yu, X., Sun, X., Cui, P., Pan, H., et al. (2020). Epidemiological and clinical characteristics of 333 confirmed cases with coronavirus disease 2019 in Shanghai, China. Transboundary and Emerging Diseases, 67(4), 1697-1707. https://doi.org/10.1111/tbed.13604

Zhang, H., Du, F., Cao, X. J., Feng, X. L., et al. (2020b). Clinical characteristics of Coronavirus disease 2019 (COVID-19) in Patients out of Wuhan from China. Research Square. https://doi.org/10.21203/rs.3.rs-15449/v1

Zhang, J. J., Dong, X., Cao, Y. Y., Yuan, Y. D., et al. (2020a). Clinical characteristics of 140 patients infected with SARSCoV-2 in Wuhan, China. Allergy, 75(7), 1730-1741. https://doi.org/10.1111/all.14238

Zhang, Y., Wu, Z., Dong, X., et al. (2020c). The Epidemiological Characteristics of an Outbreak of 2019 Novel Coronavirus Diseases (COVID-19) - China 2020. CCDC Weekly, 2(8), 113-122. https://doi.org/10.46234/ccdcw2020.032

Zhao, X.Y., Xu, X. X., Yin, H. S., Hu, Q. M., et al. (2020). Clinical characteristics of patients with 2019 coronavirus disease in a non-Wuhan area of Hubei Province, China: a retrospective study. BMC Infectious Diseases, 20, 311. https://doi.org/10.1186/s12879-020-05010-w

Zhu, J., Ji P., Pang, J., Zhong, Z., et al. (2020). Clinical characteristics of 3,062 COVID-19 patients: a metaanalysis. Journal of Medical Virology, 92(10), 1902-1914. https://doi.org/10.1002/jmv.25884 